\title{
DISEMINASI KETENTUAN BARANG YANG DIBAWA OLEH PENUMPANG DAN AWAK SARANA PENGANGKUT: STUDI KASUS MANAJEMEN HUMAS DITJEN BEA DAN CUKAI
}

\author{
Satria Adhitama \\ Politeknik Keuangan Negara STAN \\ Naskah diterima tanggal 22-04-2020, direvisi tanggal 30-06-2020, disetujui tanggal 01-07-2020
}

\begin{abstract}
Abstrak. Direktorat Jenderal Bea dan Cukai adalah organisasi pemerintah yang bertugas mengawasi dan melayani keluar masuknya barang di Indonesia. Salah satu saluran memasukkan barang ke Indonesia adalah melalui barang bawaan penumpang maskapai penerbangan dan awak sarana pengangkut udara. Garda terdepan dalam membentuk citra Indonesia khususnya DJBC. Namun komplain mengenai barang bawaan penumpang tiap tahunnya cenderung tetap bahkan mengalami kenaikan di tahun 2019. Penelitian ini bertujuan untuk melakukan analisis startegi komunikasi kehumasan dalam melakukan diseminasi ketentuan barang bawaan penumpang dan awak sarana pengangkut. Penelitian ini menggunakan paradigma konstruktivistik dengan pendekatan kualitatif deskriptif. Metode pengumpulan data dalam penelitian ini adalah wawancara. Hasil penelitian ini adalah terdapat beberapa tahapan dalam manajemen humas yang tidak dilaksanakan oleh DJBC, baik oleh Kantor Pusat DJBC dan KPU BC Soekarno Hatta. Penelitian ini dapat memberikan masukan kepada DJBC agar setiap kegiatan humas dilaksanakan dengan mengikuti tahapan-tahapan dalam manajemen humas sehingga masyarakat dapat memahami secara seksama peraturan mengenai barang bawaan penumpang dan awak sarana pengangkut.
\end{abstract}

Kata Kunci: barang bawaan penumpang, DJBC, diseminasi, humas, manajemen humas

\begin{abstract}
General Directorat of Customs and Excise of Republic of Indonesia is a government organization whose job is to supervise and service the entry and exit of goods in Indonesia. One of the channels for entering goods into Indonesia is through airline passengers' luggage and air transport crew members. The front door in shaping the image of Indonesia, especially for Customs and Excise. However, complaints about passenger luggage each year tend to remain even increase in 2019. This study aims to analyze public relations management in doing dissemination passenger luggage and crew members of the transport facilities. This research uses constructivist paradigm with descriptive qualitative approach. Data collection method in this research is interview. The results of this study are there are several stages in public relations management that are not carried out by Customs and Excise, both by the Head Office and Customs and Excise Main Service Office of Soekarno-Hatta. This Research can provide input to Customs and Excise so that each public relations activity is carried out by following the stages in public relations management so that the public can carefully understand the regulations regarding luggage of passengers and crew of transport facilities.
\end{abstract}

Keyword: Customs and Excise passenger luggage, dissemination, public relations, public relations management 


\section{PENDAHULUAN}

Dengan munculnya fenomena Global Village oleh Marshal Mc Luhan maka dunia ini bagaikan sebuah desa yang besar tak terbatas oleh jarak dan waktu. Hal tersebut disebabkan oleh kemajuan teknologi informasi dan komunikasi yang menjadikan semua manusia terhubung satu dengan lainnya. Kemajuan teknologi ini menimbulkan berbagai dampak massive secara langsung maupun tidak langsung terhadap perpindahan atau pergerakan manusia dari satu negara ke negara lain. Hal ini akan berdampak juga pada meningkatnya arus barang yang masuk dan keluar suatu negara. Barang-barang tersebut dibawa bersamaan dengan datangnya para penumpang dan petugas maskapai penerbangan (awak sarana pengangkut).

Mengingat makin meningkatnya arus manusia dan barang yang masuk di suatu negara diperlukan suatu instansi pemerintah yang mengatur dan mengawasi pergerakan barang yang dibawa oleh penumpang maupun awak sarana pengangkut yaitu Direktorat Jenderal Bea dan Cukai (DJBC) yang merupakan instansi pemerintah di bawah Kementerian Keuangan. DJBC diharapkan membuat suatu aturan yang mampu mengatur arus barang tersebut dan melakukan diseminasi informasi kepada masyarakat agar terlaksananya peran dan tugas fungsi DJBC sebagai pengumpul pendapatan negara (revenue collector) dan pelindung masyarakat (community protector).

DJBC telah menyusun suatu peraturan tentang barang ekspor dan impor yang dibawa oleh penumpang dan awak sarana pengangkut yaitu Peraturan Menteri Keuangan Nomor 203/PMK.04/2017 tentang Ketentuan Ekspor dan Impor Barang yang Dibawa oleh Penumpang dan Awak Sarana Pengangkut. Peraturan tersebut diterbitkan pada tanggal 27 Desember 2017 dan mulai berlaku sejak tanggal 1 Januari 2018. Peraturan ini menggantikan peraturan sebelumnya yaitu Peraturan Menteri Keuangan Nomor 188/PMK.04/2010 tentang Impor Barang yang Dibawa oleh Penumpang, Awak Sarana Pengangkut, Pelintas Batas, dan Barang Kiriman. Namun hingga saat ini masih banyak keluhan masyarakat mengenai barang bawaan penumpang ini seperti yang dilansir www.beacukai.go.id bahwa barang bawaan penumpang dari luar negeri seringkali menjadi permasalahan ketika diperiksa oleh Bea Cukai. Kurangnya pemahaman masyarakat terhadap ketentuan terkait barang bawaan penumpang seringkali menimbulkan keluhan, padahal prosedur dan ketentuannya sudah jelas tertuang dalam Peraturan Menteri Keuangan nomor PMK-188/PMK.04/2010 tentang Impor Barang yang Dibawa oleh Penumpang, Awak Sarana Pengangkut, Pelintas Batas, dan Barang Kiriman untuk barang-barang yang masuk Indonesia sebelum 1 Januari 2018 dan yaitu Peraturan Menteri Keuangan Nomor 203/PMK.04/2017 tentang Ketentuan Ekspor dan Impor Barang yang Dibawa oleh Penumpang dan Awak Sarana Pengangkut untuk barang-barang yang masuk Indonesia setelah 1 Januari 2018.

Selaras dengan pernyataan Menteri Keuangan Sri Mulyani bahwa selama ini barang bawaan penumpang selalu mendapat komplain dari penumpang seperti yang dilansir oleh beritagar.id dalam https://beritagar.id/artikel/berita/oleh-oleh-kurang-dari-us-500-bebas-beamasuk. Begitu juga menurut Heru Pambudi selaku Direktur Jenderal Bea dan Cukai, "terjadi aksi protes masyarakat yang dilakukan kepada petugas bea cukai di Bandara Soekarno-Hatta lantaran barang bawaan yang dari luar negeri tersebut dikenakan pajak yang cukup tinggi" seperti yang diberitakan oleh https://finance.detik.com/berita-ekonomi-bisnis/d-3648023/beacukai-akan-revisi-batasan-bea-masuk-impor-barang-penumpang. Begitu juga seperti yang diungkapkan oleh Kepala Seksi Perbendaharaan, Bea Cukai Semarang, Isnu Irwantoro pada merdeka.com bahwa masih banyak keluhan di media sosial terkait kesalahpahaman antara para penerima barang kiriman dari luar negeri, atau barang bawaan penumpang terkait aturan yang diterapkan Bea Cukai, "untuk menghindari permasalahan barang kiriman dan barang penumpang, maka kewajiban kita sebagai petugas Bea Cukai untuk memberikan edukasi dan sosialisasi kepada pengguna jasa khususnya kepada para TKI yang merupakan aset bangsa sebagai pahlawan devisa di mana sering memberikan kiriman kepada keluarga di Indonesia tetapi belum tahu ketentuan dan regulasinya." 
Selain fenomena tersebut, berdasarkan data Call Center DJBC, masyarakat menghubungi Call Center DJBC dan menanyakan serta mengutarakan keluhan tentang barang bawaan penumpang untuk tahun 2016 sebanyak 136 penelpon, 2017 sebanyak 560 penelpon, 2018 sebanyak 712 penelpon, dan di tahun 2019 ternyata menempati jumlah terbanyak yaitu 799 penelpon. Melihat hal tersebut ternyata terjadi peningkatan jumlah penelpon dalam hal barang bawaan penumpang setiap tahunnya. Oleh karena itu diperlukan peran DJBC dalam menyosialisasikan ketentuan tentang barang ekspor dan impor yang dibawa oleh penumpang kepada masyarakat luas.

Berdasarkan penjelasan tersebut di atas, peniliti ingin melihat manajemen kehumasan (public relations management) yang dilakukan oleh Direktorat Jenderal Bea dan Cukai dalam melakukan diseminasi peraturan tentang ketentuan barang ekspor dan impor barang yang dibawa oleh penumpang dan awak sarana pengangkut. Bea dan Cukai adalah garda terdepan keluar masuknya barang di Indonesia. DJBC memiliki peran penting dalam pembentukan citra bangsa Indonesia. Citra tersebut dibentuk melalui kepuasaan stakeholder yang terlibat dalam kegiatan DJBC salah satunya adalah penumpang awak sarana pengangkut yang hendak keluar atau masuk Indonesia termasuk awak sarana pengangkutnya. Perpindahan penumpang dan awak sarana pengangkut juga disertai dengan perpindahan barang. Perpindahan barang keluar masuk Indonesia perlu menjadi perhatian DJBC dengan mengeluarkan peraturan tentang barang ekpor dan impor yang dibawa oleh penumpang. Namun tanggung jawab DJBC tidak hanya sampai pada penerbitan peraturan, namun DJBC harus melakukan diseminasi kepada masyarakat luas.

Berangkat dari hal tersebut, peneliti ingin melihat bagaimana manajemen kehumasan DJBC dalam melakukan diseminasi peraturan tentang ketentuan barang ekspor dan impor barang yang dibawa oleh penumpang dan awak sarana pengangkut. Berdasarkan permasalahan di atas tujuan dari penelitian ini adalah melakukan analisis manajemen kehumasan DJBC dalam melakukan diseminasi peraturan tentang ketentuan barang ekspor dan impor barang yang dibawa oleh penumpang dan awak sarana pengangkut. Terdapat dua manfaat dalam penelitian ini, yaitu manfaat akademis yang mendeskripsikan bagaimana pelaksanaan manajemen kehumasan pada instansi pemerintah. Sedangkan manfaat praktis penelitian ini adalah memberikan manfaat bagi kalangan praktisi atau para anggota organisasi, khususnya kalangan birokrasi atau pemerintah.

\section{KERANGKA KONSEP}

Menurut beberapa ahli (Kasali, 2008) (Rumanti, 2005) (Morissan, 2006), proses public relations memiliki beberapa tahapan yang dikenal sebagai manajemen kehumasan yaitu:

\section{Definisikan Permasalahan atau Fact Finding}

Seorang praktisi PR harus dapat mengenal simtom dan penyebabnya. Dalam tahap ini praktisi PR perlu melibatkan diri dalam penelitian dan pengumpulan fakta. Selain itu, praktisi PR perlu memantau dan membaca terus pengertian, opini, sikap, dan perilaku mereka yang berkepentingan dan terpengaruh oleh sikap dan tindakan perusahaan. Pada tahap ini ditentukan: "what's happening now?". Perlu diketahui bahwa langkah ini dilakukan oleh seorang praktisi PR setiap saat secara kontinu, bukan hanya pada saat krisis terjadi.

\section{Perencanaan dan Program atau Planning}

Pada tahap ini seorang praktisi PR sudah menemukan penyebab timbulnya permasalahan dan sudah siap dengan langkah-langkah pemecahan atau pencegahan. Langkah-langkah itu dirumuskan dalam bentuk rencana dan program, termasuk anggarannya. Adalah penting bagi praktisi PR untuk mendapatkan dukungan penuh dari pimpinan puncak perusahaan karena besar kemungkinan langkah yang diambil akan sangat strategis dan melibatkan keikutsertaan banyak bagian. Adakalanya pelaksanaan program itu membutuhkan peranan langsung CEO atau pemegang saham mayoritas. Maka, rencana dan program sebaiknya berupa konsensus yang disepakati bersama. Tercakup dalam tahap ini adalah objective, prosedur, dan strategi yang diarahkan pada masing-masing khalayak sasaran. Tahapan ini akan memberikan jawaban atas pertanyaan: "what should we do and why?". Pada 
tahapan ini dilakukan penelitian untuk menentukan tujuan dan kemungkinan-kemungkinan yang terjadi.

\section{Aksi dan komunikasi atau Action and Communication}

Banyak praktisi PR yang sering melupakan kedua proses di atas dan langsung masuk ke tahap 3, yakni langsung melakukan aksi dan komunikasi berdasarkan asumsi pribadi. Meski tidak jarang tindakan itu membawa hasil yang tidak buruk, langkah ini sama sekali tidak disarankan karena terlalu tinggi risikonya bagi citra perusahaan. Manajer PR yang melakukan hal ini biasanya kurang paham ke mana citra perusahaan hendak diarahkan dan di mana ia berada kini. Aksi dan komunikasi harus dikaitkan dengan objective dan goals yang spesifik. Tahap ini menjawab pertanyaan, "how do we do it and say it?"

\section{Evaluasi programatau Evaluation}

Seorang praktisi PR perlu melakukan evaluasi atas langkah-langkah yang telah diambil. Seperti biasa, selesainya suatu permasalahan selalu akan diikuti oleh permasalahan baru. Maka, tahap ini akan melibatkan pengukuran atas hasil tindakan di masa lalu. Penyesuaian dapat dibuat dalam program yang sama, atau setelah suatu masa berakhir. Pengukuran ini menjawab pertanyaan: "how did we do?".

\section{METODOLOGI PENELITIAN}

\section{Paradigma Penelitian}

Paradigma yang digunakan dalam penelitian ini adalah paradigm konstruktivistik karena lebih mewakili cara pandang penulis untuk menjelaskan kerangka sosial yang terbentuk dalam pola pikir individu maupun kelompok yang berdasar pada akal sehat tentang bagaimana subjek penelitian memberi makna pada suatu peristiwa dalam hidupnya (Poerwandari, 2007: 22).

\section{Pendekatan Penelitian}

Pendekatan penelitian yang penulis gunakan dalam penelitian ini adalah pendekatan kualitatif. Penelitian kualitatif menurut Creswell (2007: 4) merupakan metode-metode untuk mengeksplorasi dan memahami makna yang oleh sejumlah individu atau sekelompok orang dianggap berasal dari masalah sosial atau kemanusiaan. Alasan utama penulis menggunakan pendekatan kualitatif dalam penelitian ini karena dalam penelitian ini ingin melihat secara mendalam penerapan strategi kehumasan di DJBC dalam melakukan diseminasi tentang peraturan mengenai barang ekspor dan impor yang dibawa oleh penumpang. Sehingga dapat diperoleh gambaran yang lengkap dari permasalahan yang dirumuskan dengan memfokuskan pada proses dan pencarian makna dibalik fenomena yang muncul dalam penelitian, dengan harapan agar informasi yang dikaji lebih bersifat komprehensif, mendalam, alamiah dan apa adanya.

\section{Sifat Penelitian}

Sifat Penelitian ini yaitu bersifat deskriptif. Penelitian deskriptif adalah suatu penelitian yang berusaha menggambarkan atau menjelaskan secermat mungkin mengenai suatu fenomena dari data yang ada. Menurut Moleong (2007: 6) penelitian deskriptif kualitatif adalah penelitian yang bermaksud memahami fenomena tentang apa yang dialami oleh subjek penelitian, misalnya perilaku, persepsi, motivasi, tindakan, dan lain-lain, secara holistik dengan cara deskripsi dalam bentuk kata-kata dan bahasa, pada suatu konteks khusus yang alamiah dan dengan memanfaatkan berbagai metode alamiah. Menurut Rakhmat dalam Adhitama (2011: 51) penelitian deskriptif adalah penelitian yang hanya memaparkan situasi atau peristiwa. Penelitian ini tidak mencari atau menjelaskan hubungan, tidak menguji hipotesis atau membuat prediksi (Moleong, 2007: 11).

Pemilihan metode ini berdasarkan pada pertimbangan bahwa dalam pembahasan penelitian ini akan memberikan gambaran mengenai strategi kehumasan di DJBC dalam melakukan diseminasi tentang peraturan mengenai barang ekspor dan impor yang dibawa oleh penumpang. Sifat penelitian deskriptif yang memberikan gambaran verbal dianggap sesuai dengan tujuan penelitian ini. 


\section{Strategi Penelitian}

Strategi yang digunakan dalam penelitian ini adalah studi kasus. Penelitian studi kasus adalah suatu penelitian yang berusaha menemukan makna, menyelidiki proses, dan memperoleh pengertian dan pemahaman yang mendalam dari individu, kelompok atau situasi (Emzir, 2014: 20). Tujuan dari studi kasus adalah untuk memperdalam pemahaman tentang realitas peristiwa pada konteks tertentu. Sederhananya, studi kasus mempertanyakan bagaimana dan mengapa pada suatu situasi tertentu, suatu peristiwa terjadi atau apa yang sedang terjadi (Adhitama, 2011: 49). Pemilihan strategi studi kasus didasarkan pada ketertarikan atau kepedulian peneliti untuk memahami secara utuh penerapan strategi kehumasan di DJBC dalam melakukan diseminasi tentang peraturan mengenai barang ekspor dan impor yang dibawa oleh penumpang.

\section{Metode Pengumpulan Data}

\section{a. Metode Kepustakaan (Library Research)}

Metode ini dilakukan dengan cara mempelajari dan membandingkan di antara sumbersumber informasi tertulis seperti: peraturan perundang-undangan, Keputusan Menteri Keuangan, Keputusan Direktur Jenderal, serta literatur-literatur yang mendukung penyusunan penelitian ini. Metode ini dilakukan guna memperoleh pemahaman mengenai pengertian dasar, landasan teori, dan konsep yang digunakan untuk melakukan evaluasi atas permasalahan yang dibahas.

\section{b. Metode Studi Lapangan}

Metode ini dilakukan dengan cara pengamatan dan pengumpulan data secara langsung di lapangan untuk memperoleh data akurat yang berasal dari objek penelitian berupa dokumen-dokumen, catatan-catatan, laporan-laporan, dan proses kerja atau kegiatan dari objek yang akan diteliti, serta sumber lain yang relevan dengan pokok bahasan yang dikemukakan dalam penelitian. Metode pengumpulan data dalam penelitian ini adalah wawancara. Kartini dan Kartono (1990) mendefinisikan wawancara sebagai proses tanya jawab dimana dua orang atau lebih berhadapan secara fisik. Sedangkan Cannel dan Kahn dalam Chadwik (1991) mendefinisikan wawancara riset sebagai percakapan dua orang, yang dimulai oleh pewawancara dengan tujuan khusus memperoleh keterangan yang sesuai dengan penelitian, dan dipusatkan pada isi yang dititikberatkan pada tujuan-tujuan deskripsi, prediksi, dan penjelasan sistematik mengenai penelitian tersebut.

Sukmadinata (2005) menjelaskan bahwa wawancara mendalam dilakukan dengan mengajukan pertanyaan-pertanyaan terbuka, yang memungkinkan responden memberikan jawaban secara luas. Pertanyaan diarahkan mengungkapkan kehidupan informan, konsep, persepsi, peranan, kegiatan, dan peristiwa-peristiwa yang dialami berkenaan dengan fokus yang diteliti. Informan yang diwawancarai harus memenuhi beberapa kriteria. Menurut Neuman (2003), terdapat empat kriteria informan yaitu:

a) The informant is totally familiar with the culture and is position to witness significant events makes a good informant

b) The individual is currently involved in the field

c) The person can spend time with the researcher

d) Non analytic individuals make better informant

Metode ini merupakan proses komunikasi atau interaksi untuk mengumpulkan informasi yang dilakukan dengan cara melakukan tanya jawab langsung dengan para pegawai dan pejabat di bawah seksi yang terkait dengan fungsi kehumasan.

\section{Proses Analisis Data}

Setelah semua data terkumpul maka tahap selanjutnya adalah analisis data. Dengan melakukan analisis data, hasil penelitian lapangan sudah dapat dibaca dan berguna dalam menjelaskan masalah penelitian. Analisis data kualitatif menurut Bognan dan Biklen sebagaimana dikutip oleh Moleong (2007: 248), adalah upaya yang dilakukan dengan jalan bekerja dengan data, mengorganisasikan data, memilah-milahnya menjadi satuan yang dapat dikelola, mensintesiskannya, mencari dan menemukan pola, menemukan apa yang penting dan dipelajari, dan memutuskan apa yang dapat diceritakan kepada orang lain. Teknik analisis 
data kualitatif dilakukan secara bersamaan dengan proses pengumpulan data dan proses interpretasi data.

Analisis data yang digunakan dalam penelitian ini adalah hermeneutic empiris. Menurut Sumaryono (1993) dalam Adhitama (2011: 54) proses hermeneutic dilakukan dengan cara membandingkan antara data yang diperoleh dengan kerangka pemikiran atau acuan konsep, kemudian digambarkan ulang dengan data empiris. Sedangkan empiris bermakna pengalaman, jadi hermeunetic empiris berarti bentuk interpretasi atas pengalaman yang diaalami peneliti selama penelitian berlangsung, dalam hal ini peneliti membandingkan hasil wawancara dengan kejadian yang berlangsung di lapangan. Secara garis besar proses analisis data dimulai dari data collection, data reducing, data display, dan terakhir adalah data conclusion.

\section{Alasan Pemilihan Informan}

Dalam penellitian ini terdapat beberapa informan yang menjadi subjek penelitian yaitu para pejabat atau pegawai menangani diseminasi mengenai peraturan terkait barang penumpang. Informan 1 adalah pegawai Kantor Pusat DJBC di mana pekerjaannya adalah melakukan atau menyelenggarakan diseminasi mengenai peraturan-peraturan di lingkungan DJBC. Informan 1 sudah berkerja di bidang tersebut kurang lebih 4 tahun. Sedangkan informan 2 adalah pegawai yang mengangani masalah kehumasan di lingkungan Kantor Pelayanan Utama Bea dan Cukai Tipe C Soekarno Hatta. Informan 2 sudah mengangani kehumasan khususnya di KPU BC Soekarno-Hatta kurang lebih 3 tahun.

\section{Penelitian Sebelumnya}

Penelitian ini mengacu pada beberapa penelitian sebelumnya yaitu:

a. Penelitian Lena Satlita dengan judul Reposisi Peran dan Fungsi Strategis Public Relations dalam Organisasi

Tulisan ini menguraikan konsep dasar PR, membahas peran dan fungsi strategis public relations dalam organisasi dan bagaimana mereposisi peran dan fungsi strategis ini agar PR dapat mengaktualisasikan dirinya sebagai bagian dari koalisi dominan dalam organisasi. Untuk mampu mewujudkan peran dan fungsi strategisnya, semua pihak yang terkait dengan PR perlu duduk bersama untuk mengubah paradigma, menyamakan persepsi mengenai substansi PR dan mengambil langkah-langkah untuk menghasilkan PR Profesional yang mampu memberi kontribusi terhadap organisasi khususnya dalam mengelola hubungan harmonis jangka panjang antara organisasi dengan publiknya agar reputasi organisasi tetap terjaga.

b. Penelitian Melita dengan judul Strategi Komunikasi Public Relations PT Angkasa Pura 1

(Persero) Bandara Internasional Juanda Surabaya dalam Menyosialisasikan Terminal Baru

Hasil dari penelitian ini adalah penjelasan dari strategi komunikasi perusahaan yang sesuai dengan teori Cutlip, Center dan Broom mengenai tahapan strategi komunikasi.Public Relations bersama Top Management memiliki tahapan-tahapan guna menyosialisasikan T2, di mana Public Relations bersama Top Management menentukan terlebih dahulu tujuan perusahaan baik jangka pendek maupun jangka panjang, diikuti dengan tahapan perencanaan, lalu tahapan pelaksanaan diseminasi dan dilanjutkan dengan evaluasi. Fokus strategi Public Relations untuk menyosialisasikan T2 adalah melalui media massa. Strategi komunikasi Public Relations di koordinasikan dengan Corporate Coomunication kantor pusat.

\section{ANALISIS DAN PEMBAHASAN}

\section{A. Analisis Manajemen Kehumasan DJBC}

Dalam menentukan strategi yang cocok untuk melalukan diseminasi, seorang praktisi kehumasan atau public relations harus melakukan tahapan strategi mulai mendefinisikan permasalahan, menyusun perencanaan, melakukan aksi komunikasi atau strategi komunikasi, dan mengevaluasi rangkaian kegiatan kehumasan.

Salah satu pekerjaan humas adalah melakukan komunikasi kepada pemangku kepentingan sehingga hubungan baik antara organisasi atau perusahaan dengan stakeholder semakin baik guna meningkatkan image atau citra organisasi. Oleh karena itu langkah 
pertama yang dilakukan oleh humas DJBC dalam rangka melakukan diseminasi peraturan terkait barang bawaan penumpang adalah mengetahui dengan tepat siapa stakeholder-nya atau pemangku kepentingan.

Tahapan pertama adalah mendefinisikan permasalahan. Pada dasarnya pihak DJBC sudah memahami bahwa komplain penumpang atas barang bawaan mereka yang ditegah atau ditahan oleh pihak DJBC. Hal ini senada dengan yang diungkapkan oleh informan 2, “... Banyak banget komplain itu benar, jadi komplainnya bisa macam-macam misal tentang pajak karena dia membawa barang diatas pembebasan tapi gakmau bayar pajak." Selain itu berdasarkan data Call Center DJBC, mengalami peningkatan dari tahun ke tahun. Tahun 2016 jumlah pertanyaan dan komplain sebanyak 136 kasus, tahun 2017 sebanyak 560 kasus, tahun 2018 sebanyak 712 kasus, dan tahun 2019 sebanyak 799 kasus.

Langkah berikutnya adalah penyusunan rencana atau program. Langkah ini dimulai dengan menganalisis informasi yang terkumpul untuk membuat keputusan mengenai publik, sasaran, tindakan dan strategi komunikasi, taktik dan tujuan program. Langkah kedua dalam proses public relations ini menjawab, "Kita telah mempelajari situasi ini berdasarkan apa, apa yang harus diubah, dilakukan, atau dikatakan. Dalam hal ini DJBC menentukan publiknya yaitu warga di beberapa kecamatan." Hal ini sesuai dengan penjelasan dari informan 1, "Kami sudah melakukan (diseminasi) di dua tempat. Kecamatan Pulogadung dan Kecamatan Matraman." Alasan pemilihan dua kecamatan tersebut sebagai audience diseminasi pihak DJBC adalah sebagaimana yang diungkapkan oleh informan 1 "Karena judulnya kita kan edukasi masyarakat. Jadi langsung menyentuh ke masyarakatnya. Nah terus kita berpikir kenapa ngga ke yang terkecil aja. Oke kita coba ke kecamatan ngobrol sama orang kecamatan terus mereka menanggapi dengan baik gitu. "oh oke kita juga kebetulan disini banyak forum-forum anak muda ibu-ibu yang butuh informasi seperti itu" katanya." Alasan pemilihan kecamatan tersebut sebagai sasaran diseminasi adalah "karena pertama kecamatan paling deket sama kita." Dan "kantor pusat bea cukai kan di bawah pulogadung kecamatannya. Keputusannya udah itu karena itu paling deket. Dan Kemarin kita penentuannya hanya paling dekat, dan bea cukai di bawah pulogadung. Karena ini kan acara baru, bener-benern baru kan dari kita.nah itu atas persetujuan kasubdit kita jangan diambil yang terlalu jauh-jauh atau terlalu heboh-heboh dulu. Jadi kita tuh kaya barang contoh dulu lho."

Selain melakukan edukasi atau diseminasi kepada masyarakat di Kecamatan Pulogadung dan Matraman, DJBC juga melakukan diseminasi kepada mahasiswa yang sedang melakukan kunjungan ke DJBC “... Jadi sebenernya mahasiswa yang berkunjung ke kita hmm setahun itu kita, tahun ini udah ada sebelas, sebelas kampus yang berkunjung." Salah satu kampus yang melakukan kunjungan ke DJBC adalah Universitas Indonesia, "salahsatunya adalah universitas Indonesia. Kemarin baru berkunjung. Itu kita pasti selalu memberikan edukasi tentang barang penumpang." Selain itu pihak DJBC melakukan diseminasi kepada masyarakat saat DJBC melakukan pameran "Di dalam pameran itulah kita juga memberikan edukasi mengenai barang bawaan penumpang da nada ini juga, kak. Apa, kita kan mau di dalem booth itu pasti ada poster-posternya. Poster yang kita pajangitu pasti selalu ada tentang barang bawaan penumpang.

Seperti halnya informan 1, informan 2 menginformasikan bahwa KPU BC Tipe C Soekarno-Hatta juga melakukan diseminasi barang bawaan penumpang melalui edukasi kepada mahasiswa mengingat saat ini bisnis jasa titipan atau jastip lagi booming di kalangan mahasiswa. "Tapi tahun ini kita gak bikin itu,kita bikin CGTC ke UI, temanya juga sama barang penumpang dan barang kiriman karena kan banyak jastip tuh. Jastip itu dekat dengan mahasiswa, boleh jastip silahkan tapi kewajiban pembayaran pajak tetap harus diselesaikan oleh pembawa itu."

Tahapan berikutnya adalah melakukan aksi komunikasi. Seperti dijelaskan sebelumnya beberapa strategi yang dilakukan oleh DJBC baik di instansi pusat maupun instansi vertikal yaitu KPU BC Soekarno-Hatta dalam melakukan diseminasi barang bawaan penumpang adalah melalui media sosial seperti yang diungkapkan oleh informan 1 seperti instagram @beacukairi, twitter @beacukairi, dan facebook beacukairi, dan youtube channel Direktorat Jenderal Bea dan Cukai. Saat ini DJBC sedang memfokuskan pada program diseminasi 
melalui media sosial sesuai dengan yang diungkapkan oleh informan 1 "sekarang tidak ada lagi melalui tatap muka kecuali untuk hal-hal tertentu. Jadi selama setahun sosialisasi hmm agak vakum. Udah jarang banget, dan untuk barang penumpang belum ada untuktahun ini". Bahkan diseminasi untuk barang bawaan penumpang tahun ini belum dilaksanakan secara khusus diseminasi dilakukan bersama-sama dengan tema lainnya.

Selain melalui media sosial, diseminasi dilakukan dengan memberikan edukasi kepada masyarakat di Kecamatan Pulogadung dan Matraman tentang DJBC secara umum termasuk penjelasan tentang barang bawaan penumpang. Diseminasi juga dilkukan kepada mahasiswa yang datang berkunjung ke DJBC Pusat. Tercatat tahun 2018 sudah 11 kampus melakukan kunjungan ke DJBC. Para mahasiswa tersebut diberikan penjelasan mengenai company profile DJBC yang di dalamnya terselip diseminasi tentang barang bawaan penumpang. DJBC memberikan istilah Customs Talk untuk program ini. DJBC juga melakukan diseminasi barang bawaan penumpang di sela-sela pameran yang sedang dijalankan DJBC di mana dalam satu tahun DJBC memiliki target melakukan pameran sebanyak enam kali. Selain itu pihak DJBC Pusat melakukan diseminasi mengenai barang bawaan penumpang dalam inflight magazine seperti Garuda Indonesia, Batik Air, Citilink, dan Brunai Airlines.

Berbeda dengan KPU BC Tipe C Soekarno Hatta melakukan diseminasi mengenai barang bawaan penumpang melalui suatu program yang disebut Customs Goes To Campus (CGTC), "Tapi tahun ini kita gak bikin itu,kita bikin CGTC ke UI, temanya juga sama barang penumpang dan barang kiriman karena kan banyak jastip tuh. Jastip itu dekat dengan mahasiswa, boleh jastip silahkan tapi kewajiban pembayaran pajak tetap harus diselesaikan oleh pembawa itu." Selain itu KPU BC Tipe C Soekarno-Hatta menggunakan media sosial instagram @bcsoetta dan facebook. KPU BC Tipe C Soekarno-Hatta juga membuat booth dengan nama Customs Information Day, "Kalau ig iya, kalau twitter ada @bcsoetta, facebook juga ada. Sama kegiatan kalau tahun lalu kita buat customs information day, jadi beberapa hari kita bikin booth terminal keberangkatan. Kita bikin pas mendekati libur natal, karena orang banyak yang liburan tu keluar negeri." Namun tahun 2018 Customs information Day sudah tidak dilaksanakan.

Tahap berikutnya adalah evaluasi atas program yang telah dilaksanakan. Namun baik Bea Cukai Pusat maupun KPU BC Sokarno-Hatta tidak melakukan evaluasi.

\section{B. Pembahasan}

Berdasarkan hasil analisis data yang dilakukan pada bagian sebelumnya, peneliti melakukan pembahasan yaitu:

1. DJBC menganggap barang bawaan penumpang sebagai salah aspek kepabeanan yang kurang penting. Hal tersebut berdampak kurangnya perhatian DJBC terhadap permasalahan barang bawaan penumpang padahal pemrosesan barang bawaan penumpang berada pada garda terdepan pembentukan citra Indonesia pada umumnya dan citra DJBC pada khususnya. Kurangnya perhatian terhadap barang penumpang ditandai dengan tidak adanya program khusus baik yang dilaksanakan oleh Humas DJBC Pusat atau Humas KPUBC Tipe C Soekarno Hatta tentang barang penumpang. Padahal Kementerian Keuangan baru menerbitkan peraturan terbaru tentang barang penumpang yaitu PMK Nomor 203/PMK.04/2017 tentang Ketentuan Ekspor dan Impor Barang yang Dibawa oleh Penumpang dan Awak Sarana Pengangkut yang mulai berlaku tahun 2018. Harusnya hal ini menjadi momen yang tepat untuk melakukan diseminasi kepada masyarakat tentang barang bawaan penumpang. Diseminasi memang telah dilakukan oleh DJBC kepada masyarakat tentang tentang tugas dan fungsi DJBC secara umum, bukan diseminasi barang bawaan penumpang secara khusus. Tujuan dari diseminasi tersebut adalah memberikan edukasi kepada masyarakat, dan di dalam program edukasi tersebut diselipkan diseminasi tentang barang bawaan penumpang.

2. Terkait proses penetapan strategi kehumasan DJBC dalam melakukan diseminasi barang bawaan belum lah lengkap. Hal tersebut ditandai dengan beberapa indikator yaitu:

a. Pada dasarnya tim humas DJBC sudah memahami akan permasalahan yang terjadi di lapangan bahwa terdapat banyak komplain dari masyarakat terkait barang bawaan penumpang. Namun DJBC masih mengganggap kurang urgent-nya permasalahan terkait 
barang bawaan penumpang. Hal tersebut terlihat dari tidak adanya diseminasi khusus selama tahun 2019 tentang barang bawaan penumpang dan awak sarana pengangkut. Peraturan tentang barang penumpang "diselipkan" dalam program edukasi masyarakat tentang tugas dan fungsi DJBC.

b. Manajemen humas harusnya dilakukan mulai dari fact finding, planning, communicating, dan evaluating. Namun kenyataannya terkait dengan barang bawaan penumpang, DJBC belum melakukan sesuai dengan prinsip-prinsip kehumasan.

1) Pada dasarnya data komplain masyarakat tentang barang bawaan penumpang dari Call Center DJBC bisa dijadikan sebagai dasar penyusunan program kehumasan untuk melakukan diseminasi peraturan tentang barang bawaan penumpang. Data Call Center ini bisa menjadi alasan betapa diperlukannya diseminasi tentang barang bawaan penumpang.

2) Terkait dengan proses perencanaan (planning), DJBC tidak melakukan perencanaan secara matang. Perencanaan hanya didasarkan pada budget atau anggaran yang tersedia. Tidak matangnya perencanaan DJBC dalam melakukan diseminasi tentang barang penumpang tampak dari audience yang dipilih untuk mengikuti diseminasi tanpa latar belakang yang jelas. Pemilihan audience hanya berdasarkan kedekatan tempat tinggal audience dengan kantor Bea dan Cukai. Di samping itu, Kantor Pusat DJBC dan KPU BC Tipe C Soekarno-Hatta sudah memiliki perencanaan yang lebih matang dengan membidik mahasiswa sebagai audience diseminasi mengingat mahasiswa sering melakukan perjalanan ke luar negeri.

3) Tahapan yang berikutnya adalah aksi komunikasi. Terkait aksi komunikasi, DJBC baik Kantor Pusat DJBC dan KPU BC Tipe C Soekarno-Hatta telah melaksanakan diseminasi barang bawaan penumpang dengan strategi yang tepat yaitu secara virtual. Komunikasi secara virtual dilakukan melaui media sosial baik instgram, facebook, youtube, dan twitter. Penggunaan media sosial sudah lah tepat mengingat penumpang pesawat tersebar di seluruh Indonesia. Agak sulit ketika harus melakukan clustering terhadap para penumpang pesawat. Oleh karena itu media sosial adalah alat atau strategi yang tepat dengan jangakauan audience yang sangat luas dan tersebar. Penggunaan media sosial yang banyak membuat para penumpang sangat mudah menemukan peraturan tentang barang bawaan penumpang. Hal tersebut sudah sesuai dengan teori Uses and Gratification, di mana audience memiliki kemampuan untuk memilih dan menggunakan media untuk memenuhi kebutuhan mereka. Karena masyarakat yang memilih, maka DJBC menyediakan banyak informasi di banyak saluran.

Peraturan barang penumpang juga tersedia di official magazine beberapa maskapai penerbangan seperti Airasia, Citilink, Sriwijaya, dan Express Air. Namun hal ini dirasa kurang efektif mengingat jarang penumpang yang mau membaca majalah tersebut. DJBC juga meng-hire para influencer dan blogger untuk melakukan diseminasi tentang ketentuan-ketentuan yang ada di DJBC namun tidak secara spesifik tentang barang bawaan penumpang. Hal ini cukup efektif di mana kalangan pemuda akan menyaksikan apa yang di-"promosi"-kan oleh artis idolanya. Hal ini sesuai dengan teori Two Step Flow Communication di mana proses komunikasi dilakukan melalui dua tahap. Kalangan milenial belum mengenal organisasi DJBC maka influencer dan blogger ini menjadi komunikator dalam menyampaikan pesan Bea Cukai tentang barang bawaan penumpang. Influencer dan blogger ini sangat populer di kalangan milenial.

Sebetulnya DJBC juga menjalin kerja sama dengan pihak televisi seperti Net TV (Kompas TV dan CNN TV) dan radio (KBR dan Sindotrijaya FM), namun tidak dikhususkan untuk diseminasi peraturan barang bawaan penumpang. Untuk Radio. Pada tahun 2019, DJBC hanya melakukan satu kali diseminasi tentang barang bawaan penumpang di tanggal 13 dan 14 September 2019. Pada dasarnya saat ini televisi dan radio adalah sarana yang dianggap kurang efektif dan efisien dalam menyebarkan informasi. Dengan biaya yang tinggi, namun kedua sarana tersebut sudah mulai ditinggalkan penikmatnya kecuali pada prime time. Masyarakat Indonesia cenderung memanfaatkan kemajuan teknologi internet untuk memperoleh informasi. Iklan Layanan 
Masyarakat juga sudah dibuat oleh Tim Humas DJBC namun sulit mendapatkan perhatian audience. Peraturan tentang barang bawaan penumpang juga diselipkan dalam program edukasi kepada masyarakat dan pameran. Namun beberapa diseminasi tatap muka kurang efektif dan efisien mengingat target audience yang kurang tepat. Namun di sisi lain program edukasi ini sudah tepat ketika disampaikan kepada mahasiswa di kampus-kampus sekitar Jabodetabek.

4) Sangat disayangkan tidak dilakukan proses evaluasi atas pelaksanaan diseminasi barang bawaan penumpang baik oleh Kantor Pusat DJBC maupun KPUBC Tipe C Soekarno-Hatta.

\section{SIMPULAN}

Pada dasarnya DJBC telah melakukan diseminasi barang bawaan penumpang dan awak sarana pengangkut sudah baik, namun tahapan-tahapan dalam manajemen humas belum dilaksanakan secara optimal sehingga hasilnya pun tidak maksimal dan komplain mengenai barang bawaan penumpang selalu ada bahkan trend-nya meningkat. Program kehumasan di DJBC baik di Kantor Pusat DJBC maupun KPU BC Tipe C Soekarno-Hatta ditekankan pada proses aksi komunikasi, sedangkan fact finding, perencanaan, dan evaluasi tidak dilaksanakan secara maksimal bahkan terlewati.

Agar masyarakat memahami betul peraturan barang bawaan penumpang dan awak sarana pengangkut, diseminasi perlu dilaksanakan sesuai dengan tahapan-tahapan dalam manajemen humas sehingga tepat sasaran.

\section{DAFTAR PUSTAKA}

Anggaraini, Luhani dkk. (2019). Strategi Humas Pemerintah Daerah Kabupaten Muna Barat Dalam Memberikan Informasi Kepada Masyarakat. Jurnal IImu Komunikasi UHO, Volume 4 Nomor 4 145-159. http://ojs.uho.ac.id/index.php/KOMUNIKASI/article/view/10265/7281

Anugrah, Dandan \& Winny Kresnowiati. (2008). Komunikasi Antarbudaya Konsep dan Aplikasinya. Jala Permata.

Chadwik, Bruce A. (1991). Metode Penelitian IImu Pengetahuan Sosial. IKIP Press. diterjemahkan oleh Sulistia ML

Cash, William B. \& Charles D. Stewart. (2000). Interviewing: Principles and Practices. McGraw Hill.

Cheney, George. et al. (2004). Organizational Communication in an Age of Globalization. Waveland Press Inc.

Cresswel, John W. (1994). Research Design: Qualitative and Quantitative Approaches. SAGE Publications.

Cutlip, Scott M, Center, Allen H \&, Glen. (2007). Effektive Public Relations (9th ed.). Prenada Media Group.

Daymon, C. \& Holloway, I. (2008). Metode - metode Riset Kualitatif dalam Public Relations \& Marketing Communications. Bentang.

Devito, Joseph A. (1997). Komunikasi Antarmanusia. Professional Books.

Devito, Joseph A. (2007). The Interpersonal Communication Handbook. Pearson Education.

Effendy, Onong Uchjana. (1993). Human Relations dan Public Relations. CV Mandar Maju.

Gamble, Teri Kwal \& Michael Gamble. (2003). Communication Works. McGraw Hill.

Griffin, E.M. (2003). A First Look at Communication Theor. McGraw Hill.

Goldberg, Alvin A. dan Carl E. Larson. (2006). Komunikasi Kelompok. UI Press.

Goldhaber, Gerald M. (1993). Organizational Communication. McGraw Hill.

Hall, Richard H. (1974). Organizations Structure and Process. Prentice Hall International.

Halloran, Jack. (1978). Applied Human Relations an Organizational Approach. Prentice Hall. 
Haney, William V. (1986). Communication and Interpersonal Relations: Text and Cases. Irwin Series.

Howard, Roy J. (2001). Hermeneutika: Wacana Analitis Psikososial dan Ontologis. Nuansa.

Jablin, Fredric M. \& Putnam. (2001). The New Handbook of Organizational Communication. Sage Publications.

Jefkins, Frank. (1992). Public Relations. Erlangga.

Kartini \& Kartono. (1990). Pengantar Metodologi Riset Sosial. Mandar Maju.

Kasali, Rhenald. (2003). Manajemen Public Relations. PT. Pustaka Utama Grafity.

Melita. (2015). Strategi Komunikasi Public Relations PT Angkasa Pura 1 (Persero) Bandara Internasional Juanda Surabaya Dalam Menyosialisasikan Terminal Baru (T2). Jurnal eKomunikasi, Volum 3 No 1, 1-8. http://publication.petra.ac.id/index.php/ilmukomunikasi/article/view/3838/3534

Miller, Katherine. (2005). Communication Theories, Perspectives, Processes, and Context. McGraw Hill.

Moleong, Lexy J.(2010). Metodologi Penelitian Kualitatif. PT Remaja Rosdakarya.

Morissan. (2010). Psikologi Komunikasi. Ghalia Indonesia

Morissan. (2009). Teori Komunikasi Organisasi. Ghalia Indonesia.

Morissan \& Andy Corry Wardhany. (2009). Teori Komunikasi. Ghalia Indonesia.

Muhammad, Arni. (2008). Komunikasi Organisasi. Bumi Aksara.

Mulyana, Dedy \& Solatun. (2004). Metodologi Penelitian Komunikasi dan IImu Sosial Lainnya. PT Remaja Rosdakarya.

Mulyana, Dedy. (2008). Metodologi Penelitian Kualitatif: Paradigma Baru IImu Komunikasi. PT Remaja Rosdakarya.

Nazir, Moh. (2003). Metode Penelitia. Ghalia Indonesia.

Nurul. 2018. Strategi Manajemen Humas Dalam Menyampaikan Program Unggulan Madrasah. Al Tanzim, Volume 2 Nomor 1, 1-48. https://www.ejournal.unuja.ac.id/index.php/altanzim/article/view/247/197

Neuman, William Lawrence. (2003). Social Research Methods: Qualitative and Quantitative Approaches. Ally and Bacon.

Littlejohn, Stephen W. \& Karen A. Foss. (2008). Theories of Human Communication. Thomson.

Lubis, Hari S.B. \& Martani Huseini. (2009). Pengantar Teori Organisasi. Departemen IImu Administrasi Ul.

Pace, R. Wayne \& Don F. Faules. (2002). Komunikasi Organisasi. Remaja Rosdakarya.

Pearturan Menteri Keuangan Nomor: 100/PMK.01/2008 tentang Organisasi dan Tata Kerja Departemen Keuangan

Poerwandari, Kristi E. (2007). Pendekatan Kualitatif Untuk Penelitian Perilaku Manusia. LPSP3.

Rakhmat, Jalaluddin. (2004). Metode Penelitian Komunikasi: Dilengkapi Contoh Analisis Statistik.PT Remaja Rosdakarya.

Rakhmat, Jalaluddin. (2007). Psikologi Komunikasi. PT Remaja Rosdakarya.

Ruben, D. Brent \& Lea P. Stewart. (1998). Communication and Human Behaviour. Allyn \& Bacon.

Rumanti, Assumpta Maria. SR. (2002). Dasar-Dasar Public Relations Teori dan Praktik. Gramedia Widiasarana Indonesia.

Rumondor, Alex H. (2001). Komunikasi Antar Budaya. Universitas Terbuka.

Ruslan, Rosady. (2003). Metode Penelitian Public Relations dan Komunikasi. PT Raja Grafindo Persada.

Ruslan, Rosady. (2006). Manajemen Public Relations dan Media Komunikasi. PT Raja Grafindo Persada.

Samovar, Larry A., Richard E. Porter, dan Nemi C. Jain. (1991). Understanding Intercultural Communication. Wadsworth Publishing Company.

Samovar, Larry A., Richard E. Porter, \& Edwin R. McDaniel. (2010). Komunikasi Lintas Budaya Communication Between Cultures. Salemba Humanika. 
Satlita, Lena.(2004). Reposisi Peran dan Fungsi Strategis Public Relations dalam Organisasi. Efiesiensi, Volume IV No 1 , $11-22$. https://journal.uny.ac.id/index.php/efisiensi/article/view/3802/3278

Sendjaja, Sasa Djuarsa. (2004). Teori Komunikasi. Universitas Terbuka.

Soekanto, Soerjono. (1989). Sosiologi Suatu Pengantar. RajaGrafindo.

Sukmadinata, Nana Syaodih. (2005). Metode Penelitian Pendidikan.: Rosda.

Sumaryono, E. (1993). Hermeneutik-Sebuah Metode Filsafat. Kanisius.

Susanto, A. B., dkk, Corporte Culture and Organization Culture, Jakarta: The Jakarta Consulting Group, 2008.

Sutopo, H.B., Pengantar Penelitian Kualitatif Dasar-Dasar Teoritis dan Praktik, Surakarta: Pusat Penelitian UNS, 1988.

Tom, Daniel, D., Spiker, \& Papa. (1997). Perspective on Organizational Communication. McGraw Hill.

Triastuti, Endah. (2001). Metode Penelitian Sosial Modul Intern UI. Fakultas IImu Sosial dan IImu Politik Universitas Indonesia.

Wasesa, Silih Agung. (2005). Strategi Public Relations. PT. Gramedia Pustaka Utama.

West, Rhicard \& Lynn H. Turner. (2007). Introducing Communication Theory. McGraw Hill, 2007.

Wirawan. (2008). Budaya dan Iklim Organisasi. Salemba Empat.

http://www.beacukai.go.id/wwwbcgoid/?page=media-center/berita/bea-cukai-makassarberikan-pemahaman-aturan-barang-bawaan-penumpang-pada-calon-jamaah-haji-danumrah.html Awak Sarana Pengangkut, dan Pelintas Batas.

https://beritagar.id/artikel/berita/oleh-oleh-kurang-dari-us-500-bebas-bea-masuk.

https://finance.detik.com/berita-ekonomi-bisnis/d-3648023/bea-cukai-akan-revisi-batasan-beamasuk-impor-barang-penumpang. 